\title{
İHA TABANLI OYULMA ÖLÇÜMLERİ İLE KÖPRÜ ÇOKLU AFET PERFORMANSININ DEĞERLENDIRILMESİ
}

\author{
Orkan ÖZCAN ${ }^{1}$, Okan ÖZCAN² \\ 'Öğr. Gör. Dr., İstanbul Teknik Üniversitesi, Avrasya Yer Bilimleri Enstitüsü, 34469, Maslak, İstanbul, ozcanork@itu.edu.tr \\ ${ }^{2}$ Doç. Dr., Akdeniz Üniversitesi, İnşaat Fakültesi, Yapı A.B.D, 07058, Konyaaltı, Antalya, ookan@akdeniz.edu.tr
}

\begin{abstract}
ÖZET
Akarsular üzerinde bulunan köprü ayaklarında oluşan taşkın ve akım kaynaklı oyulma, köprülerde en sık gözlemlenen göçme nedenlerindendir. Oyulmanın, köprülerde oluşturduğu göçme riskini ve deprem etkileri altında köprünün güvenliğini ne derecede değiștirdiğinin saptanması büyük öneme sahiptir. Bu nedenle, oyulma etkileri altında köprülerin güvenliğinin saptanmasında köprü ayaklarındaki oyulma mekanizmasının gerçekçi olarak belirlenmesi ve sürekli olarak takip edilerek güncellenmesi gerekmektedir. Böylelikle, köprü temel sistemlerinde oyulma kaynakl göçmeler önlenip köprü altyapı tasarımı daha güvenli olarak yapılabilecektir. Insansı hava aracı (IHA) tabanlı ölçüm sistemleri günümüz ölçüm sistemleri düşünüldüğünde yeni ve pratik bir yaklaşım sağlamakla birlikte yüksek hassasiyette ve güvenirlikte çözümler getirmektedir. Bu çalışmada, öncelikle akarsu havzasının ve özellikle nehir taşkın yatağının çok yüksek çözünürlüklü 3 boyutlu modelinin elde edilmesinde ve köprü taşıyıcı sistemindeki (kazıklı ayaklar ve kazıklı kenar ayaklar) oyulma miktarının ölçümünde IHA tabanlı ölçüm yöntemleri kullanılmıştır. Çalışma bölgesinde oluşmuş oyulma miktarı gerçekçi olarak belirlenerek, köprü ayaklarının oyulma etkisindeki davranışı kapsamlı olarak irdelenmiştir. Akarsu havzasına ait farklı zamanlarda elde edilen sayısal yüzey modelleri kullanılarak çeşitli yazılımlar ile gelecekte oluşabilecek olası taşkın etkileri ve oyulma miktarı saptanmıştır. Elde edilen veriler ışı̆̆ında oyulmaya maruz betonarme (BA) köprülerin yanal ve düşey yükler altındaki davranışı statik itme analiz yöntemi ile detaylı biçimde incelenmiştir. Analizlerde, köprü ayaklarının beklenen oyulma sonrasındaki yük ve yer değiștirme kapasitesi yapılan analiz tipine göre karșılaştırmalı olarak belirlenmiş olup, yenilenen köprü taşıyıcı sistem kapasiteleri ışığında köprü çoklu afet performansı kontrol edilmiştir. Bu amaçla, Antalya Boğaçay Deresi üzerinde bulunan ve daha önce taşkın kaynaklı oyulma sonucunda göçmüş olan BA köprü pilot çalışma olarak seçilmiştir. Bu çalışma ile özellikle akarsu yatakları üzerinde bulunan köprüler için, IHA tabanl ve sürekli güncellenebilecek köprü çoklu afet risk tespit sistemi kurulabilecektir.
\end{abstract}

Anahtar Sözcükler: Boğaçay, çoklu afet, deprem, oyulma, taşkın

\section{ABSTRACT \\ EVALUATION OF MULTI-HAZARD PERFORMANCE OF BRIDGES BY UAV-BASED SCOUR MEASUREMENTS}

Flood and stream induced scour occurring in bridge piers constructed on rivers is one of the failure reasons that is mostly observed in bridges. Scour induced failure risk in bridges and determination of the alterations in bridge safety under seismic effects has the ultimate importance. Thus, for the determination of bridge safety under the scouring effects, the scour mechanism under bridge piers should be designated realistically and should be tracked and updated continuously. Hereby, the scour-induced failures in bridge foundation systems will be prevented and bridge substructure design will be conducted safely. Unmanned aerial vehicle $(U A V)$ based measurement systems provide new and practical approach and bring high precision and reliable solutions considering recent measurement systems. In this study, in order to attain very high definition 3 dimensional models of watershed, river flood plain and to measure the amount of scour in bridge load bearing system (pile foundations and pile abutments) (UAV) based measurement methods were used. The amount of scour occurred in the study region was determined realistically and the behavior of bridge piers under scour effects was investigated extensively. Future flood effects and the amount of scour were determined with various software by using digital surface models that will be obtained at different periods for the riverbed. In the light of attained data, the behavior of reinforced concrete $(R C)$ bridges under that were exposed to scour was investigated in details by pushover analysis method under lateral and vertical loadings. In the analyses, the load and displacement capacity of bridge piers under expected scour were comparatively determined regarding the type of analysis and the multi hazard performance of the bridge was controlled in the light of updated bridge load bearing system capacity. For this purpose, the RC bridge that is located on Antalya Boğaçayl River and that was failed due to flood-induced scour was selected as the case study. With this case study, UAV based and continuously updated bridge multi hazard risk detection system can be established that can especially be used for bridges located on riverbed.

Keywords: Boğaçay, multi-hazard, earthquake, scour, flood

\section{GíRiș}

Son yirmi yılda, köprü ayaklarında oluşan yerel oyulma davranışını özetleyen kapsamlı çalışmalar yürütülmüştür (Melville, 2008). ABD’de yapılan son çalışmalarda oyulmanın köprülerin göçmesinin önde gelen nedenlerinden biri olduğu saptanmıştır (Klinga ve Alipour, 2015). Oyulma miktarının saha deneyleriyle belirlenmesi konusunda çok sayıda yöntem geliştirilmiştir. Öncelikle sonar ve yer radarı (GPR) kullanılarak oyulma tespit edilmesi yöntemleri 
kullanılmıştır (Topczewski vd., 2016; Burrell vd., 2008). Ayrıca, diğer bir yöntem köprülere yerleştirilen ivmeölçerler yardımıyla köprü titreşim özelliklerindeki değişimden faydalanarak köprü ayaklarındaki oyulma miktarlarını tespit etme yöntemidir (Liao vd., 2016; Bao vd., 2017). Bunun yanında, köprü ayaklarına algılayıcı yerleştirilerek radyo dalgaları kullanımı ile anlık oyulma derinliği tespit edilmiştir (İbrahimy ve Motakabber, 2015). Belirtilen yöntemlerin, köprü ayağında doğrudan ölçüm yöntemi düşünüldüğünde gerek uygulama zorluğu gerek ekonomik nedenlerden ötürü oyulma ölçümlerinde genelde güçlükleri bulunmaktadır. İHA tabanlı olarak, mevcut literatürde taşkın analizi konusunda çeşitli çalışmalar yapılmış olup (Tamminga vd., 2015) herhangi bir oyulma ölçüm yöntemine rastlanılmamıştır. Önceki çalışmalarda, İHA'lar tarafından temin edilen hava fotoğraflarıyla 3 boyutlu nokta bulutu üretim iş akışları incelenmiş ve doğruluk analizlerini hem bağımsız sayısal arazi modellerin üzerinden hem de doğrulama noktaları veri setleri üzerinden gerçekleştirilmiştir. Bu çalışmalarda Structure from Motion (SfM) tekniği ile elde edilen doğrulukların, daha geleneksel yöntemlerle elde edilen yüksek çözünürlüklü topografik etüt metodları ile benzer büyüklükte olduğu gösterilmiş̧ir (James ve Robson, 2012; Fonstad vd., 2013; Turner vd., 2012; Clapuyt vd., 2016; Kaiser vd., 2014). Bu çalışmaların yanı sıra insansız hava araçları ile nehir batimetrisinin modellenmesi çalışmaları da mevcuttur (Flener, 2013; Legleiter, 2012). Yapılan çalışmalarda, sığ sularda yüksek çözünürlüklü görüntülerden elde edilen batimetrik veriler gerçek değerler ile doğrulanmış ve yüksek korelasyon değerleri elde edilmiştir. Bu çalışmada, betonarme (BA) köprü ayaklarındaki oyulma derinliğinin hem dönemsel sığ nehir debisi altında hem de taşkın sonrası deprem durumlarında köprülerin güvenliğini ne ölçüde etkilediği saptanmıştır. Bu kapsamda, öncelikle seçilmiş olan Antalya Boğaçay Deresi üzerinde bulunan köprülerin kazıklı ayak ve kazıklı kenar ayaklarındaki mevcut oyulma miktarı hassas biçimde insansız hava aracı (IHA) ölçümleri ile belirlenmiştir (Şekil 1).

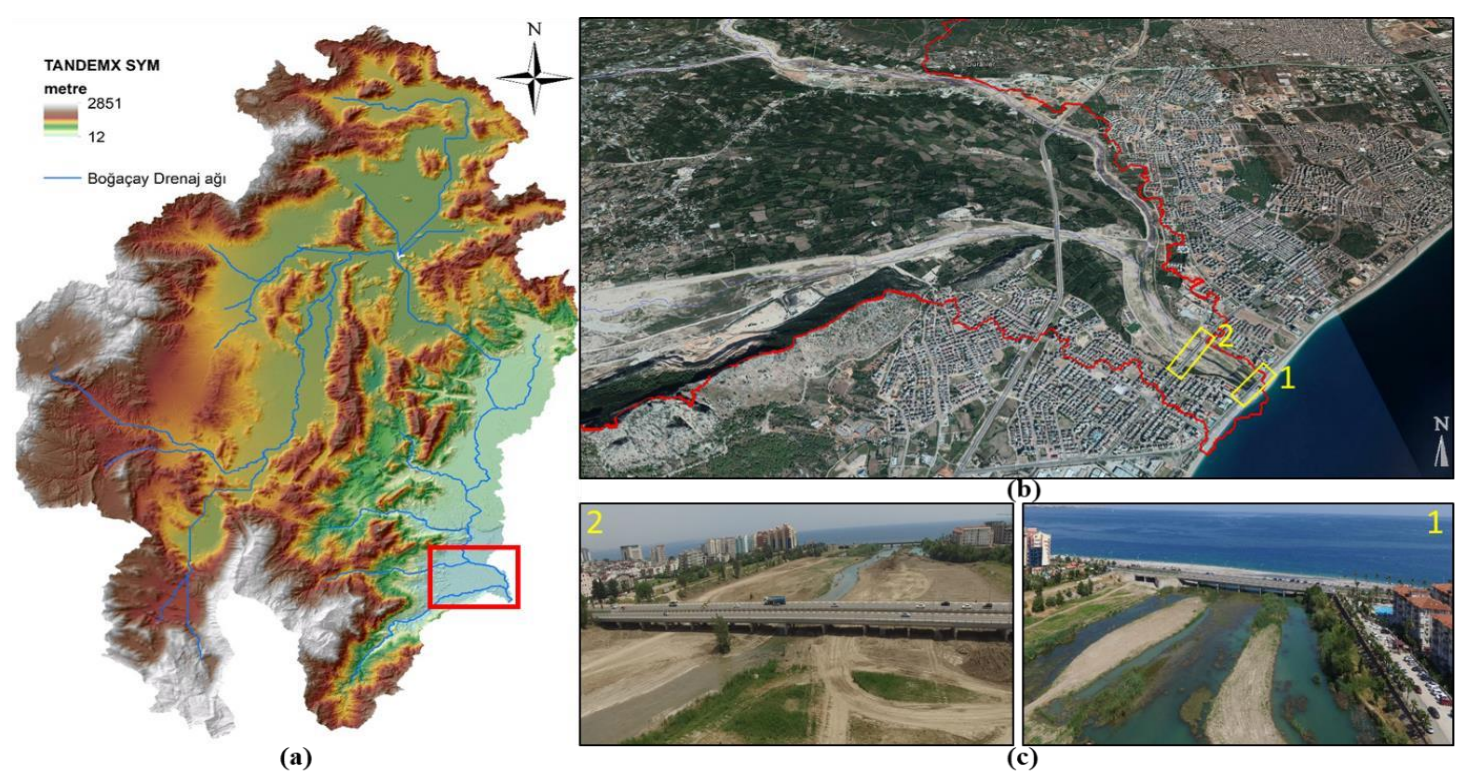

Şekil 1. Çalışma alanında; (a) altlık olarak kullanılan TanDEM-X sayısal yüzey modelinden üretilmiş Boğaçay havzası ve drenaj ağı haritası, (b) ölçüm yapılan köprülerin konumlarını gösterir harita ve (c) köprülerin havadan çekilmiş fotoğrafları.

\section{UYGULAMA}

Seçilen havzaya ait taşkın analizleri, taşkın kaynaklı oyulma miktarları için gerekli akarsu havza sayısal yüzey modelleri ve köprü ayaklarındaki yerel oyulma tespiti İHA ile yapılmıştır. İlk aşamada belirlenen taşkın debisi ve buna karşı gelen köprü ayakları için beklenen oyulma miktarları HEC-RAS yazılımı oyulma modülü ile tahmin edilmiştir. Böylece daha önce oyulma kaynaklı göçme yaşamış veya hasar görmüş köprüler için çoklu risk performans değerlendirmesi ve hızlı performans değerlendirme yönteminin geliştirilmesi için ön analizler yapılmıştır. Köprü ayağı, kazıkları ve kazık gruplarının sonlu eleman modelleri yapılarak taşkın sonrası oyulma etkisi altındaki ayak, kazık ve kazık gruplarının köprü sismik performansı üzerindeki etkileri saptanmıştır. Köprü modelleme teknikleri detaylı olarak irdelenerek en uygun model belirlenmiştir. Ayrıca, köprü performans değerlendirmesi için seçilen en uygun modelle, havza ile ilgili taşkın analizlerinden elde edilen veriler birleştirilerek analiz edildiğinde, çalışmanın ana amaçlarından biri olan çoklu risk altında köprü performans değerlendirme yöntemi geliştirilmiştir. Bu yöntem ile birlikte, köprülerin olası oyulma etkileri altında modal karakteristiklerinin ve yanal performansının değişimi kullanılmış olan modelleme teknikleri ile saptanmıştır. Bu veriler ışığında, İHA tabanlı elde edilen veriler, HEC-RAS sonuçları ve SAP2000 analiz programı ile seçilen bir köprünün oyulma etkileri altında davranışı belirlenmiştir. Bunun 
için Antalya ili içinde bulunan ve daha önce taşkın kaynaklı oyulma etkisi ile yıkılmış olan Boğaçay-1 Köprüsü seçilmiştir.

\subsection{Boğaçay-1 Köprüsü Durum Çalışması}

Boğaçay-1 Köprüsü, Antalya'nın Konyaaltı ilçesinde yer almaktadır. Köprü, Devlet Kara Yolu Akdeniz Bulvarı'nı taşımaktadır ve koordinat (enlem ve boylam) olarak: $36^{\circ} 51^{\prime} 9^{\prime \prime} \mathrm{K}$ ve $30^{\circ} 37^{\prime} 31^{\prime \prime}$ D'da yer almaktadır. Ayrıca, 157.6 m uzunluğunda olup 7 açıklığa sahiptir. Üst yapı, $22 \mathrm{~cm}$ kalınlıkta yerinde dökme BA tabliyeyi destekleyen ve ağırlık merkezleri arasında $1.65 \mathrm{~m}$ mesafeye sahip 9 adet basit mesnetli I tipi öngerilmeli beton (ÖG) kirişlerden oluşmaktadır. Boğaçay Köprüsü, 2 tanesi kenarayak olmak üzere 8 BA köprü ayağına sahiptir. Her ayakta, üst yapıyı kolonlara bağlayan bir başlık kirişi, 1,2 m'lik bir genişliğe, 1,1 m yüksekliğe ve $13 \mathrm{~m}$ uzunluğa sahiptir. Kolon uzunluğu üst yapının merkezi ve temel arasındaki düşey uzaklık olarak 7,8 m olup kolonlar $2.5 \mathrm{~m}$ x $1 \mathrm{~m}$ kesitlere sahiptir. Köprü ayağı ve başlık kirişleri monolitik olarak dökülmüştür ve her ayak ortalama uzunluğu $27 \mathrm{~m}$ olan sekizli kazık grubu ile desteklenmektedir (Şekil 2a). Köprü elemanlarının yanında köprünün etkileşim hâlinde bulunduğu zeminin modellenmesinde Reese ve diğ. (2001), McVay ve diğ. (2004) tarafından önerilen yöntemlere göre iki tabakadan (çakıl ve kum) oluşan zeminin p-y ve t-z eğrileri kullanılmıştır.

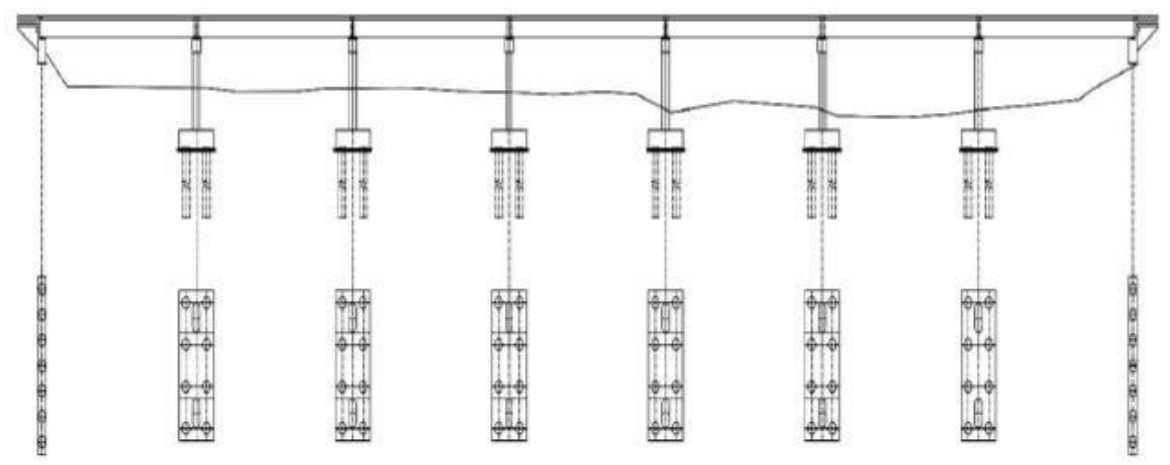

(a)

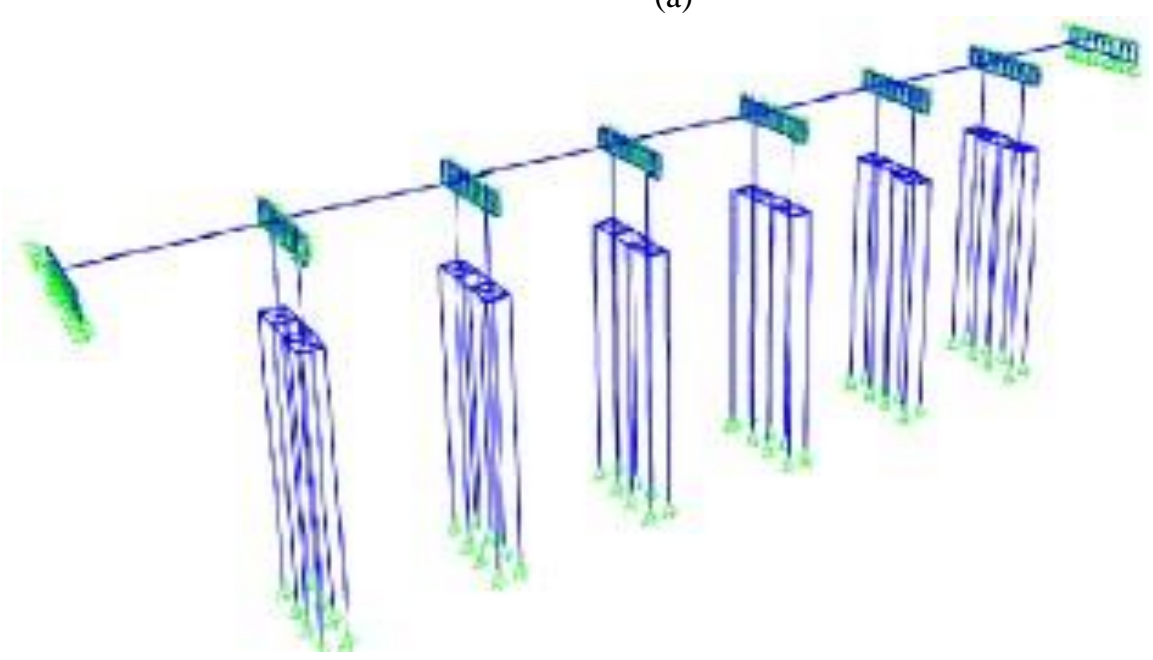

(b)

Şekil 2. (a) Köprü boy kesiti ve (b) Köprü modeli.

Köprü modelinin oluşturulmasında ve oyulmanın köprü yanal performansına etkisinin saptanmasında SAP2000 yazılımı kullanılmıştır. SAP2000, yapısal sistemlerin statik veya dinamik, doğrusal veya doğrusal olmayan analizini gerçekleştiren genel amaçlı bir sonlu elemanlar programıdır. Köprü kolonlarını ve kazıklarını modellemek için elastik ötesi davranış gösterebilen elemanlar kullanılmıştır. Betonun gerilme-gerinme ilişkisi için kullanılan sargılanmış beton modeli, köprü ayak ve kazıklarının kapasitelerini ve davranışlarını belirlemek için benimsenmiştir. Köprü ayağı ve kazık bileşenlerin doğrusal olmayan modellenmesi, fiber esaslı doğrusal olmayan elemanlar kullanılarak yapılmıştır. Kolon ve kazıklar için kullanılan fiber mafsal modeli (Fiber PMM), farklı eksenel yük seviyeleri için elemanların moment - eğrilik davranışını tanımlamakta kullanılmıştır. Köprü modeli Şekil 2b'de gösterilmiştir.

Zemin modellenmesinde plastik davranış gösterebilen p-y ve t-z eğrileri, kazık davranışının modellenmesinde benimsenmiş olan zemin yapı etkileşim modelleridir. P-y yöntemi, yanal yük altında kazık temellerin analizi ve 
tasarımı için kullanışlıdır. Basit bir analiz olanağı sağlar ve doğrusal olmayanlık, derinlik ile zemin sertliğinin değişimi ve zeminin profilinin katmanlanması gibi unsurların kolaylıkla dikkate alınmasını sağlar. Çalışma bölgesinde, su tabakasının zemin yüzeyinde olduğu kabul edilmiş olup, zemin etkin birim hacim ağırlı̆̆ $17 \mathrm{kN} / \mathrm{m}^{3}$ olarak kullanılmıştır. Zemin katkısı da dahil olmak üzere kazık grubu sertliği, bir gruptaki kazıkların sayısıyla çarpılan tek kazık tepkisinden daha az olabilir. Böyle bir durumda, kazık grubunda ait modülü azaltılabilmekle birlikte bu çalışmada kazıklar birbirlerinden yeterince ayrık olarak bulunduğundan grup kazık yanal kapasitesinde azaltma uygulanmamıştır. Ayrıca, kazık başlığının sağladığı yanal direnç genellikle uygulamada olduğu gibi göz ardı edilmiştir. Kazığın çeşitli derinliklerinde p-y eğrileri (kuvvetin yer değiştirme ile ilişkisi) p'nin yaylar arasındaki kazığın kol uzunluğu ile çarpılmasıyla hesaplanmıştır. Oyulmanın varlığında, köprü temel sisteminin bir kısmı zemindeki yanal desteğini kaybettiğinden dolayı oluşan kaybı modellemek için kazıkların üstünden oyulma derinliğine kadar olan yaylar çıkarılmıştır. Kum tabakaları için kullanılmış olan p-y eğrileri oyulmasız ve tam oyulma durumları için Şekil 3a ve 3b'de gösterildiği gibidir.

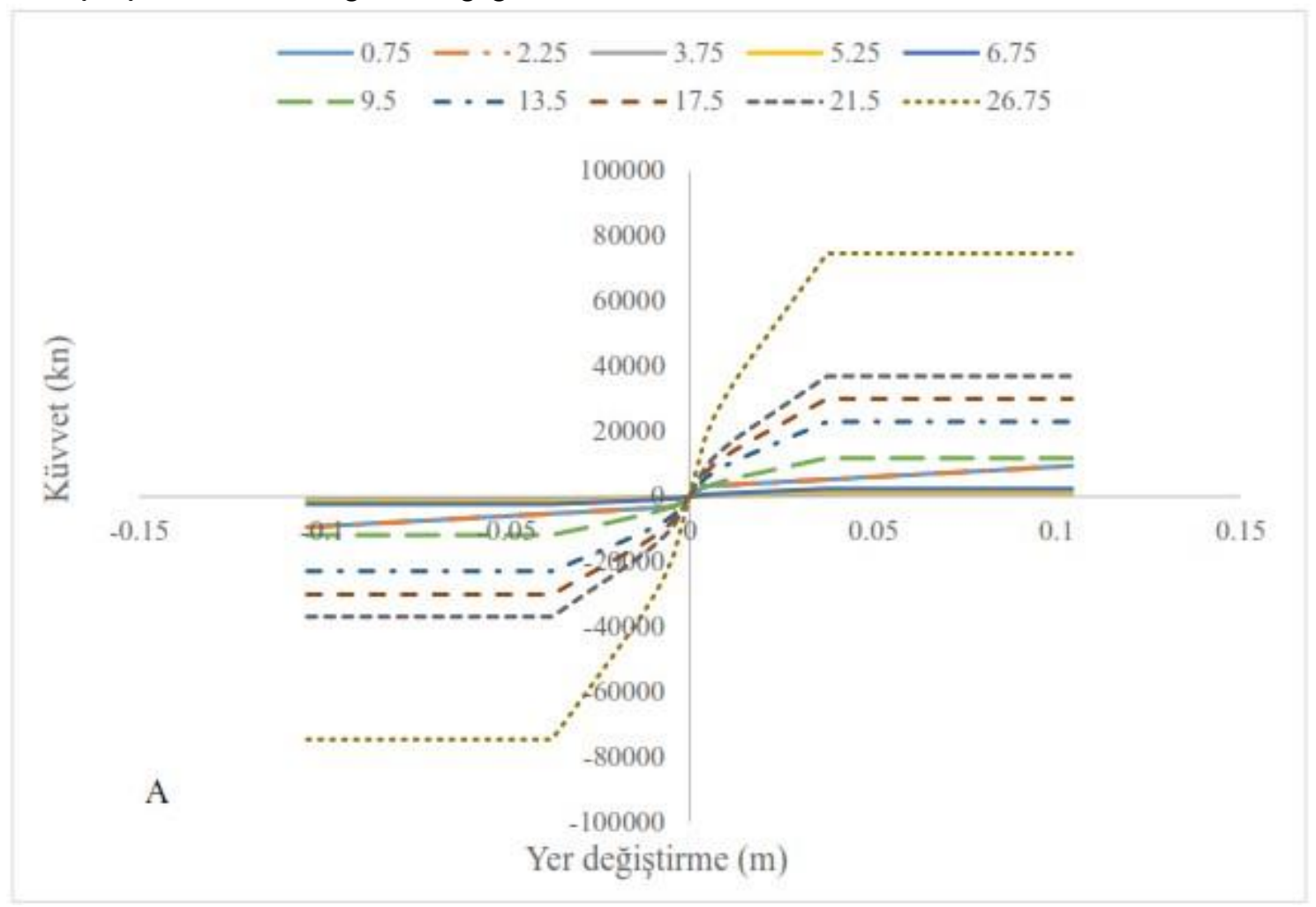

a) Oyulmasiz durum

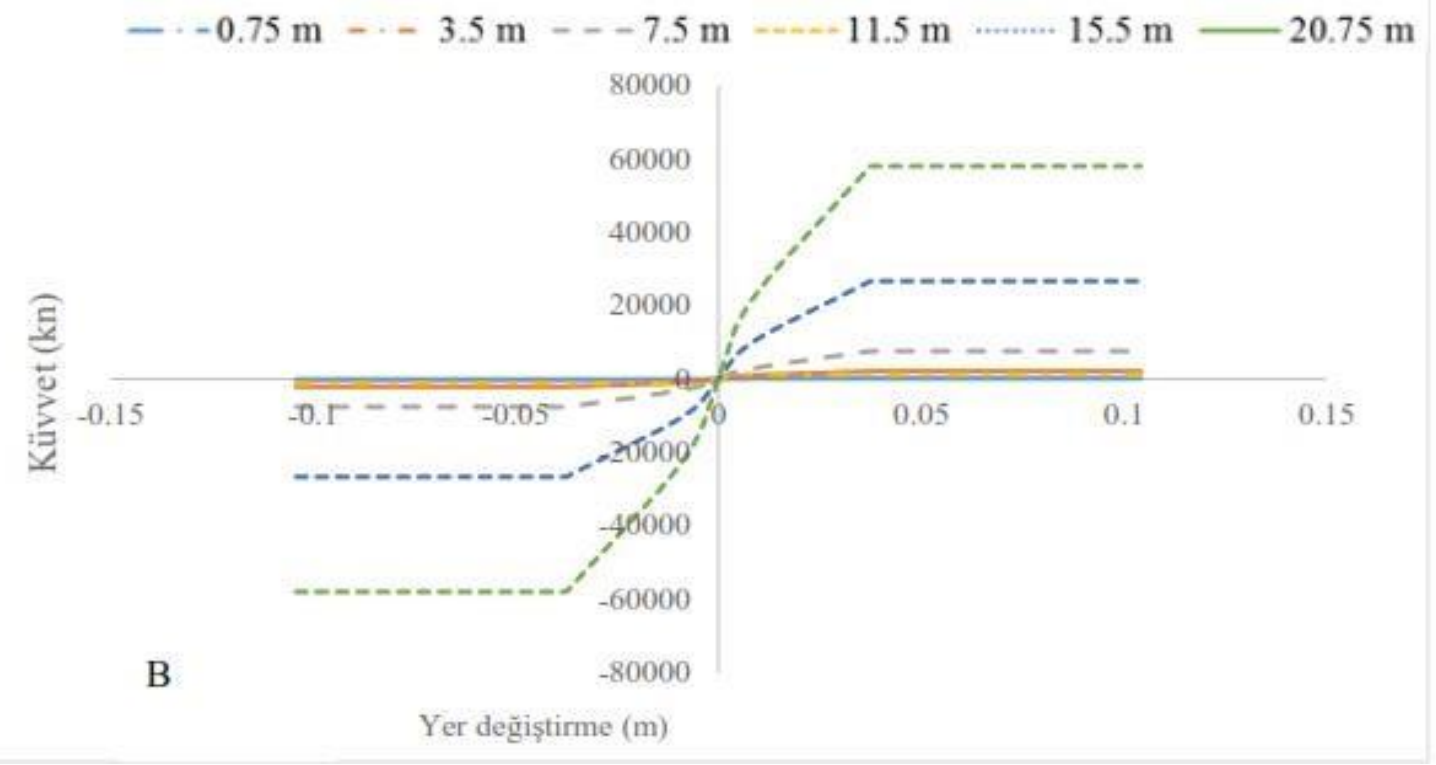

b) tam oyulmalı durum

Şekil 3. Derinlikle değişen p-y eğrileri(Kum için). 
Oyulma etkileri altında köprülerin yapısal tepkilerini belirlemek için iki tür analiz yapılmıştır: (i) modal analiz ve (ii) boyuna ve enine itme analizi. Yapılan analizlerde 5 oyulma senaryosu düşünülmüştür. İlk önce yapı oyulma olmamış hâliyle modellenmiş ve analiz edilmiştir. Daha sonra oyulma derinliği 1.5 m'lik artışlarla 6 m oyulmaya kadar arttırılmış ve yapının tepkisi bu oyulma hâllerinin her birinde incelenmiştir. Yapılmış olan modal analizlerde 500 mod, iki temel yönde \%90'dan fazla kütle katılım sağlamak için kullanılmıştır. Modal analiz sonucunda oyulma olmayan ve en fazla 6 m'lik oyulma olan her oyulma şartları için yapının temel periyotları elde edilmiştir.

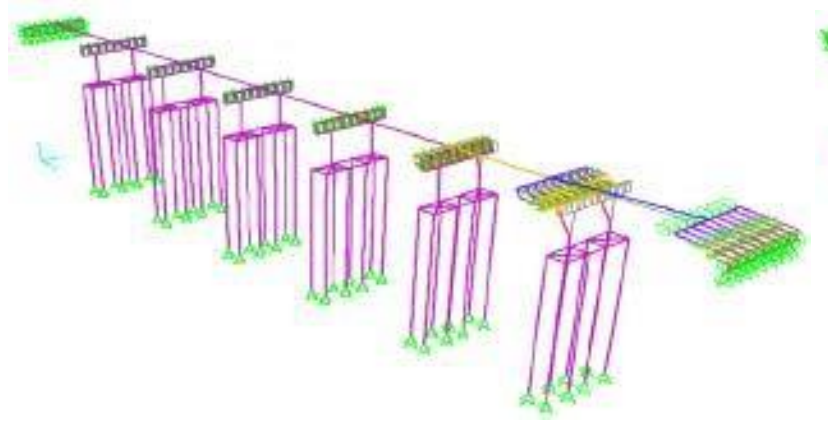

a) Oyulmasiz durum

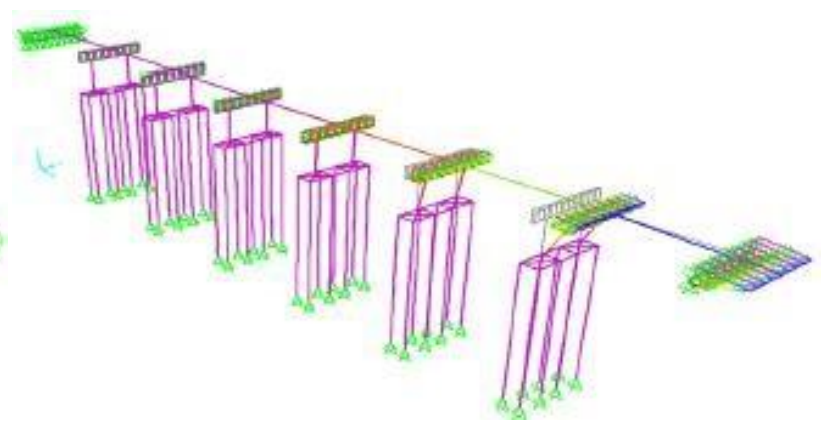

b) Tam oyulmalı durum

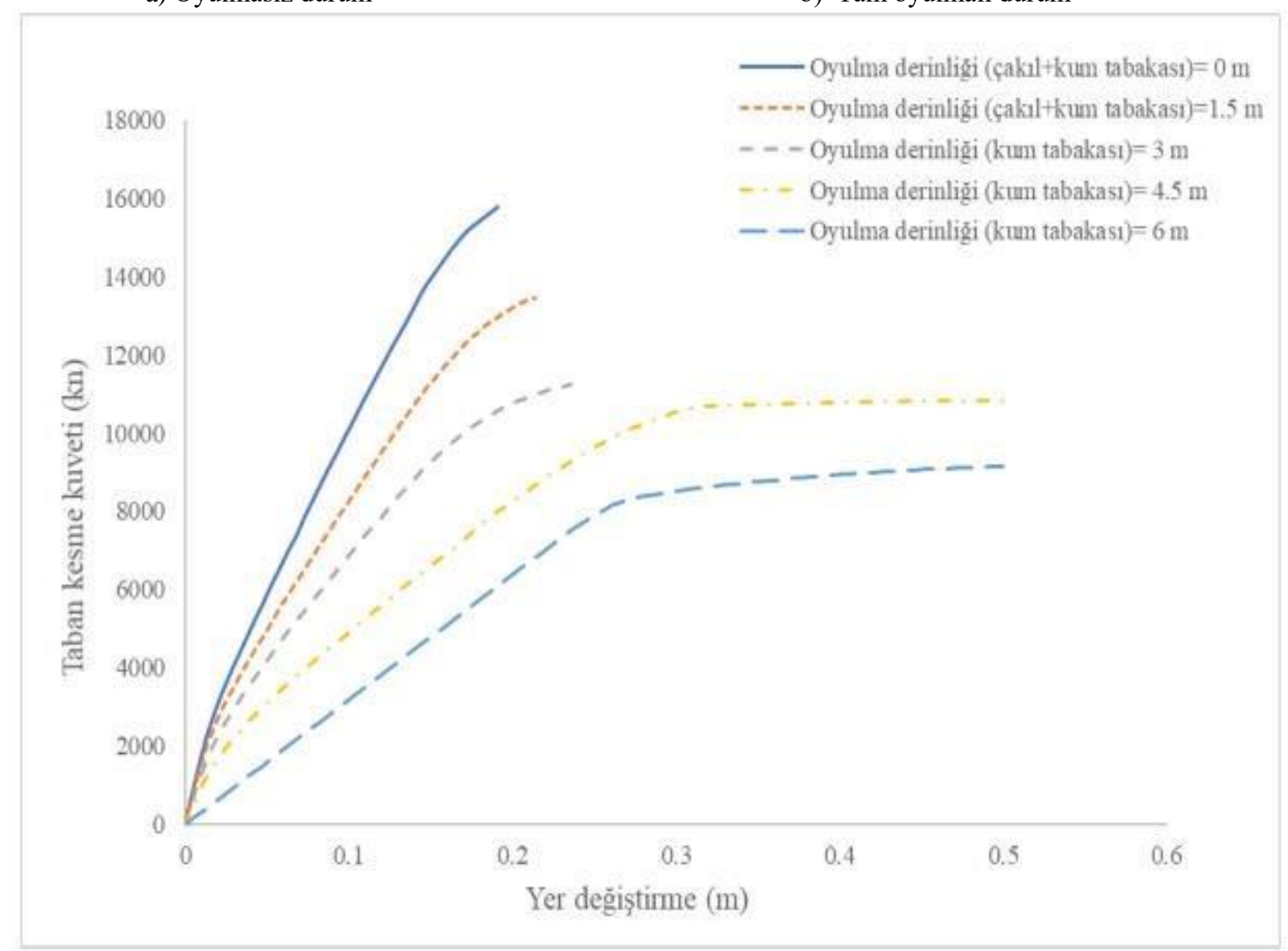

c) Boyuna doğrultuda köprü itme analiz sonuçları

Şekil 4. Köprü modal karakteristiklerinin değişimi.

Köprü temel periyodu, oyulma artışıyla artmakta olup temellerde yanal direncin serbest bırakılması nedeniyle köprü rijitliğinin azaldığını göstermektedir. Böylece, esneklikteki bu artışın köprünün temel periyodunu arttırdı̆̆ saptanmıştır. Oyulma olmadığ 1 durumda temel periyodu boyuna doğrultuda olarak $3.048 \mathrm{~s}$ iken tam kapsamlı oyulma durumunda 3.820 s'ye ulaşmıştır. Temel periyodundaki artış yaklaşık \% 25'tir (Şekil 4a ve 4b). Köprünün oyulma etkileri altında yanal davranış1, SAP2000'de gerçekleştirilen bir dizi doğrusal olmayan itme analizi ile belirlenmiştir. Yer değiştirme kontrollü itme analizi, köprü yanal davranışını belirlemek için yürütülmüştür. İtme analizine dair kesme kuvveti - yer değiştirme (itme) eğrileri değişik oyulma derinlikleri için elde edilmiştir. Genel olarak, taban 
kayma kuvvetleri ile oyulma derinliği arasında azalma eğilimi vardır. Her oyulma durumu için analiz sonuçları yanal yükün etkileri altında incelendiğinde, köprünün yanal kapasitesi, oyulma derinliği arttıkça azalmaktadır. Taban kesme kuvveti azalması, tam oyulma ve oyulmanın olmadığı durum ile karşılaştıııldığında \% 50'nin üzerindedir (Şekil 4c). Böyle bir davranışın başlıca nedeni, plastik mafsalların, köprü ayağı / kazıkların net yüksekliklerinin yükselmesinin bir sonucu olarak daha düşük kesme kuvvetlerinde oluşmasıdır.

\section{SONUÇLAR}

Akarsu havzası içinde bulunan köprülerinin çoklu afet riski altındaki performansının belirlenmesi bu tip sanat yapılarının ekonomik ömrünün tespit edilmesinde ve gerekli güçlendirme çalışmalarının yapılmasında büyük öneme sahiptir. Bu nedenle, çalışmada öncelikle akarsu havzasının karakteristikleri incelenmiş olup, taşkın durumunda köprü ayaklarının maruz kalacağı yükleme koşulları belirlenmiştir. İHA tabanlı ölçüm yöntemi ve çoklu afet riski altında köprü performans değerlendirmesi yöntemi geliştirilmesi ile literatürdeki önemli bir boşluğun doldurulması hedeflenmiştir. Böylelikle, akarsular üzerinde yapılmış olan köprüler için kullanılabilecek, sürekli güncellenen verilere dayanan ve öz devimli bir hızlı performans değerlendirme yöntemi bu analizler ışığında geliştirilebilecektir.

\section{KAYNAKLAR}

Bao, T., Swartz, R.A., Vitton, S., Sun, Y., Zhang, C., Liu, Z., 2017. Critical insights for advanced bridge scour detection using the natural frequency. Journal of Sound and Vibration, 386, 116-33.

Burrell, J., Gurrola, H., Mickus, K., 2008. Frequency domain electromagnetic and ground penetrating radar investigation of ephemeral streams: case study near the Southern High Plains, Texas. Environment Geology, 55, 116979 .

Clapuyt, F., vd., 2016. Reproducibility of UAV-based earth topography reconstructions based on StructurefromMotion algorithms. Geomorphology, 260, 4-15.

Flener, C., 2013. Calibrating deep water radiance in shallow water: adapting optical bathymetry modeling to shallow river environments. Boreal Environment Research, 18, 488-502.

Fonstad, M.A., Dietrich, J.T., Courville, B.C., Jensen, J.L., Carbonneau, P.E., 2013. Topographic structure from motion: a new development in photogrammetric measurement. Earth Surface Processes and Landforms, 38, 421-430.

İbrahimy, M.I., Motakabber, S.M.A., 2015. Bridge Scour Monitoring by Coupling Factor Between Reader and Tag Antennas of RFID System. International Journal of Geomate, 8 (16), 1328-32.

James, M.R., Robson, S., 2012. Straightforward reconstruction of 3D surfaces and topography with a camera: accuracy and geoscience application. Journal of Geophysical Research, 117, F03017.

Kaiser, A., Neugirg, F.,Rock, G., Müller, C., Haas, F., Ries, J., Schmidt, J., 2014. Small-scale surface reconstruction and volume calculation of soil erosion in complex Moroccan gully morphology using structure from motion. Remote Sensing, 6, 7050-7080.

Klinga, J. V., ve Alipour, A., 2015. Assessment of structural integrity of bridges under extreme scour conditions. Eng. Struct., 82, 55-71.

Legleiter, C.J., 2012. Remote measurement of river morphology via fusion of LiDAR topography and spectrally based bathymetry. Earth Surf. Process. Landforms, 37, 499-518.

Liao, K.W., Cheng, M.Y., Chiu, Y.F., Lee, J.H., 2016. Preliminary bridge health evaluation using the pier vibration frequency. Construction and Building Materials, 102, 552-63.

McVay, M.C., Niraula, L., 2004. Development of PY curves for large diameter piles/drilled shafts in limestone for FBPIER (No. Final Report).

Melville, B., 2008. The physics of local scour at bridge piers. Fourth International Conference on Scour and Erosion. 
Reese, L. C., 2001. Van Impe. WF, Single Piles and Pile Groups Under Lateral Loading, AA Balkema, Rotterdam.

Tamminga, A.D., Eaton, B.C., Hugenholtz, C.H., 2015. UAS-based remote sensing of fluvial change following an extreme flood event. Earth Surface Processes and Lanforms, 40, 1464-1476.

Topczewski, L., Ciesla, J., Mikolajewski, P., Adamski, P., Markowski, Z., 2016. Monitoring of scour around bridge piers and abutments. Transport Research Arena - TRA2016, 14, 3963-71.

Turner, D., Lucieer, A., Watson, C., 2012. An automated technique for generating georectified mosaics from ultrahigh resolution unmanned aerial vehicle (UAV) imagery, based on Structure from Motion (SfM) point Clouds. Remote Sensing, 4, 1392-1410. 